\title{
The Effect of Miswak and Fluoride Toothpastes on Dental Plaque- A Comparative Clinical and Microbiological Study
}

\author{
${ }^{1}$ Aseem Sharma, ${ }^{2}$ Reena Ranjit Kumar, ${ }^{3}$ Stanley Mathew, \\ ${ }^{4}$ Akshay Gupta, ${ }^{5}$ Sachin Upadhyay \\ ${ }^{1}$ Senior Lecturer at Institute of Dental Sciences Jammu \\ ${ }^{2}$ Professor and head at DJ Dental College Modinagar \\ ${ }^{3}$ Private consultant orthodontist \\ ${ }^{4}$ Professor and head Indira Gandhi Government Dental College Jammu \\ ${ }^{5}$ Post graduate student
}

\begin{abstract}
The oral cavity harbors a diverse and abundant number of complex oral pathogens causing different oral diseases. The development of dental caries and periodontal diseases has been found to be closely associated with various gram positive and gram negative microrganisms. Miswak has been documented as a potent antibacterial aid and its use is encouraged in different countries because of its good taste, texture, availability, cost and beneficial effect on teeth and supporting tissues. Different researches have been carried out to evaluate the antimicrobial effects of miswak.
\end{abstract}

Aim: The aim of this randomized, clinical trial was to compare the effect of miswak and fluoride toothpastes on the count of $S$. mutans in dental plaque.

Methods:15 subjects were used in the study. Patients were instructed to brush their teeth twice daily, refrain from any other oral hygiene procedures, and continue their routine dietary habits throughout the duration of the study. They were also instructed to use the assigned toothpaste for 14 days and refrain from brushing the night before their dental visit in order to allow for plaque accumulation. The patients were examined at the first visit as baseline record and after 14 days for comparison. Pooled plaque samples were collected from buccal surface upper incisors for bacterial count.(streptococcus mutans) Plaque samples were further sent for culture.

Result: No statistically significant difference was noted between both groups.

Conclusion: Both toothpastes have a good antimicrobial effect on caries producing bacteria, thus can be used in patients as a regular home care preventive aid in combating dental caries.

Keywords: Antimicrobial effects, Miswak, oral pathogens, salvadorapersica.

\section{Introduction}

Dental caries is a significant public dental health problem, .It is not a self-limiting disease and without proper oral hygiene, it will progress until the tooth is destroyed. It is a multifactorial disease in which, streptococci mutan in dental plaque, play important roles. Tooth brushing and flossing removes dental plaque and antiseptic mouthwashes kills some of the bacteria that help in formation of plaque. Good oral hygiene is necessary for the healthy teeth, gum and fresh breath. Fluoride and plant extracts incorporated in toothpastes help to protect teeth by binding with enamel to make it stronger. It is of importance to look at the role plants play in oral hygiene as a number of them have medicinal properties . A study has shown that the concentrations of fluoride in biofilms are significantly increased after brushing with fluoridated toothpaste. The uptake of fluoride into the dental biofilm that was not removed by brushing is regarded as the main cariostatic effect of fluoride containing toothpastes. Miswak Salvadorapersica is a small upright evergreen tree or shrub with white branches and aromatic roots, seldom more than $30 \mathrm{~cm}$ in diameter and three meters in height, has been used for centuries as oral hygiene tools . Chemical analysis of S. persica demonstrated the presence of many components exhibiting antimicrobial effect of miswak aqueous extract.

The aim of this study was to:

1. Compare the effect of miswak and fluoride toothpastes on the count of S. mutans in dental plaque.

Patient Selection:

\section{Subjects and Methods}

30 patients of the Department of Orthodontics and Dentofacial Orthopaedics were included in this study. Informed consent from the patients was obtained before the study.

Selected patient fulfilled the following criteria

1). Patient undergoing Fixed Orthodontic treatment . 
2). Apparently healthy with no history of systemic diseases.

3). None of them were under antimicrobial agents since one month of sampling.

4). Oral rehabilitation was done

- $\quad$ Floridated tooth paste

\section{Materials}

- (Dabur MISWAK) herbal toothpaste formulated with pure extract of Miswak.

\section{Methods}

All patients were instructed to brush their teeth twice daily, refrain from any other oral hygiene procedures, and continue their routine dietary habits, throughout the duration of the study. The patients were divided into two groups of 15 each. 15 patients were given floridated toothpaste and 15 were given miswak toothpaste. They were instructed to use the assigned toothpaste for 14 days and refrain from brushing the night before their dental visit in order to allow for plaque accumulation as mentioned in previous studies . The patients were examined at the first visit as baseline record and after 14 days for comparison. plaque samples were collected from buccal surface of clinically sound upper incisors using sterile toothpicks for bacterial count. Plaque samples were placed in the screw capped vial .Plaque samples were inoculated in the agar media.

\section{Statistical Analysis}

Numerical data were presented as mean and standard deviation (SD) values. A logarithmic transformation ( $\log 10$ transformation) of each CFU count was performed to normalize the data before statistical evaluation because of the high range of bacterial counts. Student's t-test was used to compare between the two groups. Paired t-test was used to study the changes after treatment within each group.
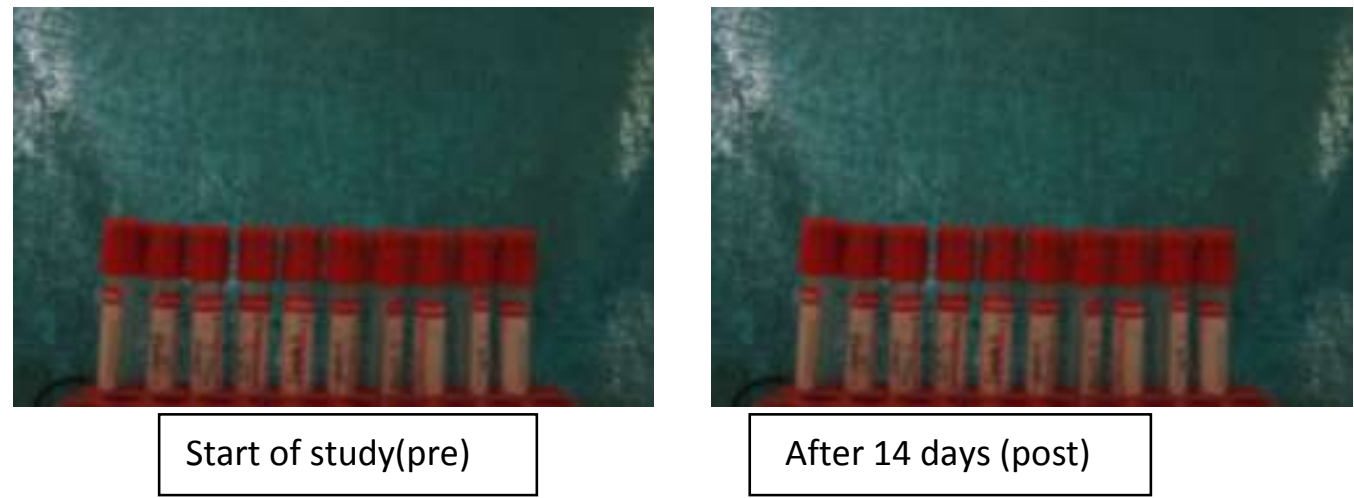

VI. Results

As regards the percent change, no statistically significant difference was noted between both groups.

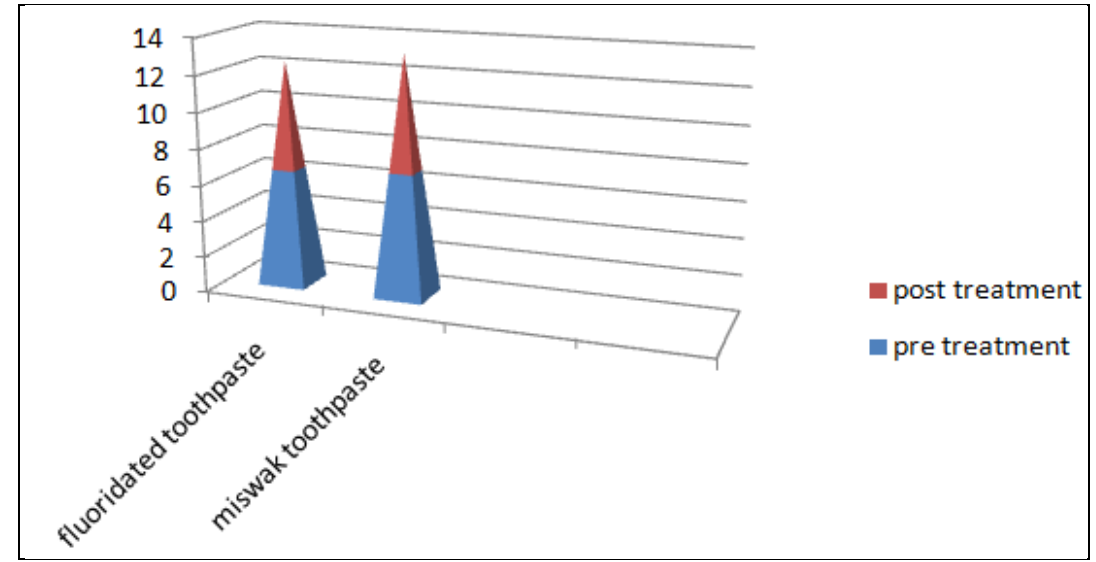

Table 1

\section{Discussion}

Patients were selected from the Department of Orthodontics and Dentofacial Orthopaedics. Plaque samples were collected by using explorer. Collected plaque samples were used to determine levels of S. mutans. Plaque samples were collected from buccal surface of upper incisors as they have high concentration of plaque. 
Decrease in the mean bacterial count has-been observed in both groups, toothpastes have reduced S. mutans when used over a period of 14 days. Similarly several studies demonstrated the antibacterial effect of miswak on S.mutans . Study demonstrated an immediate antibacterial effect of Miswak with significant reduction of S. mutans. Also found that toothpaste containing Miswak extract was significantly more effective compared to fluoridated toothpaste,and attributed the anticaries effect of miswak to its fluoride content.

Similarly another study showed that rinsing with Miswak extract resulted in protracted elevation of plaque $\mathrm{pH}(>6.0)$. The difference in plaque $\mathrm{pH}$ between Miswak extract and water rinse was statistically significant at 30 minutes $(\mathrm{p}<0.01)$ (Sofrata, 2010). The elevated plaque $\mathrm{pH}$ with Miswak rinse could be due to a buffering capacity of the Miswak extract, salivary stimulation due to Miswak taste, and/or antibacterial activity against acidproducing bacteria. Also (Edgar \& O'Mullane, 1996) explained that Miswak stimulated salivary secretions as it has a relatively strong taste, thus washing out and diluting acids.

Similarly several studies demonstrated the antibacterial effect of miswak on S. mutans and found that S. persicahas an antibacterial effect on different types of bacteria, including mutans streptococci (Al- Lafi \& Ababneh, 1995; Almas et al., 1997; Almas, 1999; Almas \& Al-Bagieh, 1999). Another study demonstrated an immediate antibacterial effect of Miswak with significant reduction of S. mutansand non-significant reduction in Lactobacilli when comparing Miswak sticks with toothbrush (Almas\& Al-Zeid, 2004). Also (Faiez, 1995) found that toothpaste containing Miswak extract was significantly more effective compared to fluoridated toothpaste, and attributed the anticaries effect of miswak to its fluoride content. On the contrary testing the antibacterial effect of fresh Miswak pieces embedded in inoculated agar plates indicated that Miswak had very strong antibacterial activity. The inhibitory effect of miswak was most pronounced on P. gingivalis, A. actinomycetemcomitans, and $\mathrm{H}$. influenzae, less on S. mutans and least on Lactobacillus acidophilus, which indicated that Miswak extract was more effective against Gram negative than Gram-positive species (Sofrata, 2010).

\section{Conclusion}

From the study the following conclusions can be drawn: Both toothpastes have a good antimicrobial effect on caries producing bacteria, thus can be used in patients as a regular home care preventive aid in combating dental caries.

\section{References}

[1] Sofrata A. : SALVADORA PERSICA (MISWAK) An effective way of killing oral pathogens. ISBN .2010; 978-91-7409-915-7.

[2] Edgar W. M. \& O'mullane D. M. : Salivary and Oral Health: clearance of substances from the oral cavity implications for oral health. In: ASSOCIATION, B. D. (ed.)1996; Second edition ed. London.

[3] Al lafi T, Ababneh H. : The effect of the extract of the miswak (chewing sticks) used in Jordan and the Middle East on oral bacteria.1995; Int Dent J; 45:218-222

[4] Almas K, Al-Bagieh N, Akpata ES. : In vitro antibacterial effect of freshly cut and 1- month-old Miswak extracts. Biomed Letters; 1997;56:145 \pm 149 ..

[5] Almas K. : The antimicrobial effects of extracts Azadirachtaindica (Neem) and Salvadorapersica (Arak) chewing sticks.Indian J Dent Res; 1999;10:23- 26.

[6] Almas K, Al-Bagieh NH. : The antimicrobial effects of bark and pulp extracts of miswak, Salvadorapersica. Biomed Letters;1999; 60:71 775 .

[7] Almas and Al-Zeid Z. : The immediate antimicrobial effect of a toothbrush and miswak on cariogenic bacteria: Aclinical study . 2004 ;Contemp Dent Pract; 5:105-114.

[8] Faiez, N.H. Miswac: The natural toothbrush. The Journal of clinical Dentistry, 1995 ;8(5), 125-129.

[9] Sofrata A. : SALVADORA PERSICA (MISWAK) An effective way of killing oralpathogens. ISBN2010; 978-91-7409-915-7.

[10] Mohan kumar K P . Priya N K. Madhushankari G S cariogenic efficacy of herbal and conventional toothpaste .a comparative in vitro study . j Int Oral Health 2013 Apr5(2):8-13 